\title{
Development of a scale to evaluate mobility in dogs
}

\author{
Construção de uma escala de mobilidade do cão
}

\section{Luísa Carneiro Vasconcelos Basto Gonçalves ${ }^{\mathrm{II}}$ II* $^{*}$ Ana Daniela Gomes Araújo Simões ${ }^{\mathrm{II}}$ Darryl Lynn Millis ${ }^{\text {III }}$ Augusto José Ferreira de Matos ${ }^{\mathrm{I}, \text { IV }}$}

\section{ABSTRACT}

The purpose of this study was to develop and to assess the psychometric characteristics of a mobility scale for dogs. The original ten questions were reduced using validation process. One hundred and twenty three dog owners were invited to answer the questionnaire. Internal consistency, factor analysis, floor and ceiling effect and construct validity were studied. Good internal consistency (Cronbach's Alpha=0.854) was determined with two items eliminated. The instrument comprises 8 final questions, each of which has five possible answers (never, rarely, sometimes, often and always) scored between 0 and 4 or between 4 and 0 (for the items with inverse score). Three hypotheses proposed for the construct validity were verified: 1) gender does not influence $\operatorname{dog}$ mobility $(P=0.584)$; 2) mobility decreases with age $(P<0.001)$; 3) dogs with orthopaedic or neurological diagnosed pathologies have less mobility (median score (P25; $P 75) 46.9 \%(31.3 ; 68.8)$ ) than healthy dogs (median score (P25; P75) $81.3 \%(71.9 ; 93.8))(P<0.001)$. Total score range was 0 to 32 points, with higher values indicating greater mobility of dogs. The Dog Mobility Scale was capable of assessing mobility in dogs, with good psychometric characteristics, and is simple and inexpensive to apply in clinical practice.

Key words: Canine, mobility, psychometric methodology, questionnaire, validation.

RESUMO

Este estudo teve como objetivos construir e avaliar as caraterísticas psicométricas de uma escala de mobilidade para cães. O questionário, constituído inicialmente por dez questões, foi submetido a um processo de validação, recorrendo à redução do número de questões. Cento e vinte e três donos de cão foram convidados a responder ao questionário. Foram estudados a consistência interna, a análise fatorial, os efeitos teto e chão e a validade de construto do instrumento. Foi encontrada uma boa consistência interna (Cronbach's Alpha $=0.854$ ) com a eliminação de dois itens. O questionário/escala final ficou composto por oito questões, cada qual com cinco respostas possíveis (nunca, raramente, às vezes, frequentemente e sempre) pontuadas entre zero e quatro ou entre quatro e zero (para os itens com pontuação inversa). Três hipóteses propostas para a validade de construto foram verificadas: 1) o gênero não influencia a mobilidade $(P=0.584) ; 2)$ a mobilidade declina com o envelhecimento $(P<0.001)$; 3) cães com patologia ortopédica ou neurológica diagnosticada apresentam menor mobilidade (median score (P25; P75) 46.9\% (31.3; 68.8)) do que cães saudáveis (median score (P25; P75) 81.3\% (71.9; 93.8)) ( $P<0.001)$. A escala final resulta numa pontuação de 0 a 32 pontos em que maior pontuação corresponde à maior mobilidade. A Escala de Mobilidade do Cão avaliou, com boas caraterísticas psicométricas, a mobilidade de um grupo díspar de cães, revelando-se simples e econômica na sua aplicação na prática clínica.

Palavras-chave: Canina, metodologia psicométrica, mobilidade, questionário, validação.

\section{INTRODUCTION}

The objective analysis of daily mobility in dogs, albeit important in the prevention and treatment of many pathologies, is hampered by several factors including human individual and personal

Instituto de Ciências Biomédicas Abel Salazar (ICBAS), Universidade do Porto, Porto, Portugal.

"Escola Superior de Saúde de Vale do Sousa e de Vale do Ave (ESSVS/ESSVA), Instituto Politécnico de Saúde do Norte (IPSN), Rua Central de Gandra, n 1317, 4585-116 Gandra, Paredes, Portugal. E-mail: luisavgoncalves@gmail.com. "Corresponding author.

IIIDepartment of Small Animal Clinical Sciences, University of Tennessee College of Veterinary Medicine, Knoxville, TN, USA.

${ }^{\text {IV }}$ Centro de Estudos de Ciência Animal (CECA), Instituto de Ciências (ICETA), Tecnologias e Agroambiente da Universidade do Porto, Portugal. 
interpretation as well as behaviour and temperament characteristics of the animal, both individual and breed-related (HSU \& SERPELL, 2003).

In an attempt to overcome such difficulties, veterinary professionals have developed or adapted many different scales aiming to measure acute and chronic pain, life quality, or lameness aiming to standardize the evaluation of an animal's status and response to treatment. (HOLTON et al., 2001; MILLIS, 2004; WISEMAN-ORR et al., 2004; BROWN et al. 2007; HESBACH, 2007; QUINN et al., 2007; REID, 2007; HIELM-BJORKMAN et al., 2011; LAVAN, 2013).

One problem with subjective scores is the agreement between subjective and objective measurements (e.g. force platforms, pressure walkways). Indeed, although the former are quicker, valuable, and more practical to use in routine clinical practice (JOHNSON et al., 1997; BALLAGAS et al., 2004; MONK et al., 2006; JANDI \& SCHULMAN, 2007; JERRE, 2009), mild conditions may still remain undetected (QUINN et al., 2007; WAXMAN et al., 2008).

Although pain and quality of life are extremely well studied in dogs, (BROWN et al., 2007; HIELM-BJORKMAN et al., 2011), it is still necessary to improve the knowledge and deepen the study of another aspect of canine function, mobility. This dimension has received relatively little attention at individual level, but rather has been studied in association with signs of disease or clinical features, as a sub-category of pain or quality of life. Mobility assessment during daily activities would allow evaluation of the dog's ability to move and perform its daily functional routines, as well as quantification of changes over time. Besides their correlation with clinical situations, mobility changes do not always imply pain, lameness or other clinical signs but rather precede them. Therefore, recognizing changes in mobility may allow early treatment or prevention.

Functional mobility includes all postures and movements involved in daily function, from maintenance of static recumbency, sitting and standing postures, to the dynamic transitions to and from these positions, which requires appropriate concentric and eccentric motor control (HESBACH, 2007). A properly developed and validated scale or questionnaire to assess mobility is lacking in the veterinary literature.

The assessment of mobility in a new and strange environment, such as a veterinary clinic, may be hindered by the influence of such conditions on a dog's behaviour. Consequently, it is believed that assessment of an individual dog's mobility should rely on observations in a familiar environment, and the owner may be the appropriate person to evaluate it by providing a link regarding mobility assessment between domestic and clinic environments. Evaluation of mobility in the home environment may also provide valuable information regarding the degree of return to function, which may represent the best indication of a successful outcome following treatment (MILLIS, 2004). In addition, having the owner as the only evaluator, the interobserver differences are eliminated (QUINN et al., 2007; WAXMAN et al., 2008).

The purpose of this study was to develop and to assess the psychometric characteristics of a mobility scale for dogs (Dog Mobility Scale (DMS)). To further evaluate the validity of the construct scale, the following hypotheses were tested: (1) there is no mobility variation based on dog gender; (2) older dogs have reduced mobility; (3) dogs with pathology that may affect mobility have reduced mobility.

\section{MATERIALS AND METHODS}

The development of the questionnaire underwent sequential procedures. Ten initial questions were created by a veterinarian and a physiotherapist to assess simple and vital activities, such as eating, sleeping, and elimination habits (micturition and defecation), and more active abilities, including running, jumping and climbing stairs. Beyond the questions to characterize each dog (name, age, gender, breed, weight, vaccination, type of feeding), an additional question was made about the diagnosis of potential mobility-limitation conditions. Dogs with orthopaedic or neurological conditions formed the group "with pathology". Questions were then presented to an expert committee composed of 2 veterinarians, 2 physiotherapists and 1 dog owner to further evaluate grammar and language issues, individual value and meaning to the composite scale, as well as the utility of interpretation and understanding of the information determined from the scale. A final evaluation was then performed by application of the scale by 6 dog owners to detect any other imperfections.

One hundred and twenty three dog owners were invited to complete the questionnaire, face to face, after explaining the objective and procedures of the study and signing an informed consent declaration. Inclusion criteria were that no changes were made to the household environment. Data were excluded if the owners declared that they did not 
observe their dog's activity routines. No individual owner information was disclosed. This study was approved by the scientific commission and the board direction of the $\mathrm{PhD}$ program in veterinary sciences of the University of Porto, Portugal.

\section{Statistical methods and Data Analysis}

Psychometric methodology was used to analyse the scale. Internal consistency was evaluated through inter-item correlation methods (r) and Cronbach's Alpha $(\alpha)$. For the first analysis, an interitem correlation coefficient under 0.30 was considered to be weak, between 0.30 and 0.7 moderate, and over 0.7 as a strong correlation.

Factor analysis was used to verify the way items grouped themselves into different dimensions, setting 0.4 as an acceptable minimum for correlation between original variables and main components. The final scale score was calculated by summing all items followed by conversion to a percentage: [(score- minimum $) /($ maximum - minimum $\left.){ }^{*} 100\right]$. Floor and ceiling effect was studied to understand if the extreme scores of the scale (lower and higher) were visible between the others. In case of the absence of the effect, it is positive for the content validity of this instrument and also for it responsiveness and reliability (TERWEE et al., 2007).

Mann-Whitney test was applied to study the construct validity, comparing male with female scores, and scores of dogs with and without known conditions that may affect mobility. The Spearman's Correlation Coefficient was used to compare the scale scores with the dogs' ages, and Kruskal-Wallis test was applied to compare the scale scores between quartiles of dogs' ages.

All statistical analyses were tested as 2 -tailed with $\alpha=0.05$. Analyses were performed using SPSS version 19.0 for Windows (Chicago, IL).

\section{RESULTS}

During the review process, the expert committee made changes primarily related to syntax and text to apply to veterinary context. No changes were deemed necessary after the preliminary test so the questionnaire was considered to be adequate for use.

The final sample consisted of 123 ownerdog pairs, with 62 female (50.4\%) and 61 male dogs. Fifty-eight dogs were mixed breed $(47.2 \%)$ and Labrador retrievers $(n=11 ; 8.9 \%)$, German shepherds $(n=6 ; 4.9 \%)$, Poodles $(n=5 ; 4.1 \%)$, Pinscher $(n=4$; $3.3 \%)$, Cocker Spaniel $(n=4 ; 3.3 \%)$ and Golden retrievers $(n=3 ; 2.4 \%)$ were the most represented pure breeds. Dogs weighed 1.2 to $52 \mathrm{~kg}$, with a mean of $19.34 \mathrm{~kg}$. The median age of dogs was 54.0 months (percentile 25: 36 months; percentile 75: 120 months). Initial exploratory data analysis, using bar graphs and frequency measures, resulted in the inversion of scores of items 1, 2, 7, 8, 9 and 10. None of the options had a frequency of zero and there was only one missing answer, for item 4.

\section{Internal consistency}

In order to validate the scale for its proposed objective, its internal consistency was analysed for the sum of all items. The Cronbach's alpha was 0.822 . After analysing the individual item-total correlations and elimination of individual items from the scale, items 4 and 8 were removed because of weak total item correlation and an increased Cronbach's alpha after their elimination (Table 1). After such eliminations, the final Cronbach's alpha was 0.854 .

Factor analysis

The factor analysis allowed identification of a solution with one component explaining 50.8\% of the total variance. Final solution was identified by the factor loads in the correlations matrix (over 0.4 for every item), with no need for elimination of any other item (factor loads between 0.541 for item 3 and 0.831 for item 2).

Floor or ceiling effect

Each of the eight items has five possible answers. The total score range was 0 to 32 points, with higher values indicating greater mobility of dogs. Ten dogs $(8.1 \%)$ reached the maximum score and none had the minimum score. Thus, because these values are lower than $15 \%$ there was no floor or ceiling effect.(TERWEE et al., 2007).

\section{Construct validity and testing of hypotheses} Comparison of genders was not found to be statistically significant. There was a statistically significant difference between dog's quartiles ages and the mobility scale score $(\mathrm{P}<0.001)$. Finally, the reported orthopaedic or neurological conditions, which were diagnosed by veterinary practitioners, were hip dysplasia $(4 ; 3.25 \%)$ osteoarthritis (3; $2.44 \%$, vertebral disc herniation $(2 ; 1.63 \%)$, elbow dysplasia, spondylitis, amputation and limb dysmetria (each one with 1 case; $0.81 \%$ ). A statistically significant difference $(\mathrm{p}<0.001)$ was reported in mobility score between dogs diagnosed with and without orthopaedic or neurologic conditions (Table 2). 
Table 1 - Dog mobility scale internal consistency.

\begin{tabular}{|c|c|c|c|}
\hline & Item-Total Correlation & $\begin{array}{c}\text { Cronbach's Alpha if } \\
\text { eliminated item }\end{array}$ & $\begin{array}{l}\text { Global Cronbach's } \\
\text { Alpha }\end{array}$ \\
\hline $\begin{array}{l}1 \text {...did you notice difficulty in the first steps after waking } \\
\text { up and arising? (inverted) }\end{array}$ & 0.640 & 0.792 & 0.822 \\
\hline $2 \ldots$ did he/she show difficulty climbing stairs? (inverted) & 0.731 & 0.781 & \\
\hline $3 \ldots$.. did he/she desire to play? & 0.437 & 0.812 & \\
\hline 4 ...did he/she run? & 0.598 & 0.795 & \\
\hline $\begin{array}{l}5 \ldots \text {.. did he/she climb easily to the sofa, bed or some other } \\
\text { higher plane? }\end{array}$ & 0.608 & 0.795 & \\
\hline $\begin{array}{l}6 \text {...did he/she show fatigue during longer walks? } \\
\text { (inverted) }\end{array}$ & 0.551 & 0.801 & \\
\hline $\begin{array}{l}7 \text {...did he/she show changes in the way he/she walked? } \\
\text { (inverted) }\end{array}$ & 0.641 & 0.793 & \\
\hline $\begin{array}{l}8 \text {... did he/she spend too much time in the same position? } \\
\text { (inverted) }\end{array}$ & 0.573 & 0.800 & \\
\hline
\end{tabular}

Items translated into English.

\section{DISCUSSION}

Although clinical metrology has received relatively little attention in veterinary medicine, there are some dog owner questionnaires that compare scores either with some form of disease severity or surgical outcome, some of them having proved to correlate to veterinary assessment and force platforms data (HIELM-BJORKMAN et al., 2011; BROWN et al., 2013; CHRISTOPHER et al., 2013; WALTON et al., 2013). As with the creation of the DMS, the main concern of these instruments is to focus on the domain studied. Questionnaires must be precise to evaluate the primary domain and ordinary use and with a clear grammar to prevent client misunderstanding (INNES \& BARR, 1998; HUDSON et al., 2004; BOYD et al., 2007).

The validity procedure removed two items from the DMS because they resulted in a total weaker item correlation, and did not contribute to the validation of mobility. A dog's reaction to food is not dependent only on mobility, but also on hunger or positive behavioural reinforcement, while position or changing of position during sleeping also did not have significant correlation to dog mobility. The item reduction resulted in a final scale with better internal consistency. The Cronbach's alpha of 0.854 , considered by the literature as a strong value, represents good internal consistency (TERWEE et al., 2007).

The construct validity of the DMS was supported by the testing of specific hypotheses concerning the measured concept, mobility. Although there were no differences between males and females, there may be differences between intact and neutered animals of both genders, to be confirmed in future studies. As expected, younger dogs had higher mobility values than older dogs (BROWN et al., 2010), may be due to fewer neurological and orthopaedic conditions and behavioural differences related to youth (SIWAK et al., 2002). The first important decline in mobility occurred in dogs over 55 months of age; a second decline, even greater, occurred in dogs older than 120 months of age. The presence of an orthopaedic/neurological condition also revealed to be a factor of decrease in the mobility of dogs. Similar decreases of mobility have been reported in other studies (POY et al., 2000; MARSOLAIS et al., 2003; COOK, 2010; MARSH et al., 2010; RAGETLY et al., 2010; SANCHEZ-BUSTINDUY et al., 2010;). The absence of floor and ceiling effects on this DMS suggests favourable sensitivity of this scale for evaluation of additional validity studies (INNES \& BARR, 1998; TERWEE et al., 2007).

The DMS, developed in this study is an easy and quick way to obtain useful information, has the added advantage that it does not require owners to have trained evaluation skills and may be valuable to assess dogs with early medical conditions.

Suggestions for future studies include exploration of the responsiveness of the DMS to treatments for mobility disorders, further evaluation of its reproducibility, additional validation, and comparison with other qualitative methods of assessing mobility, such as tracking movement with GPS technology (criterion validity).

In conclusion, the Dog Mobility Scale evaluated in this study demonstrated good psychometric properties and may be a clinically useful and quick instrument to assess mobility in dogs. 
Table 2 - Median (percentile 25; percentile 75) of the Dog Mobility Scale score by demographic groups.

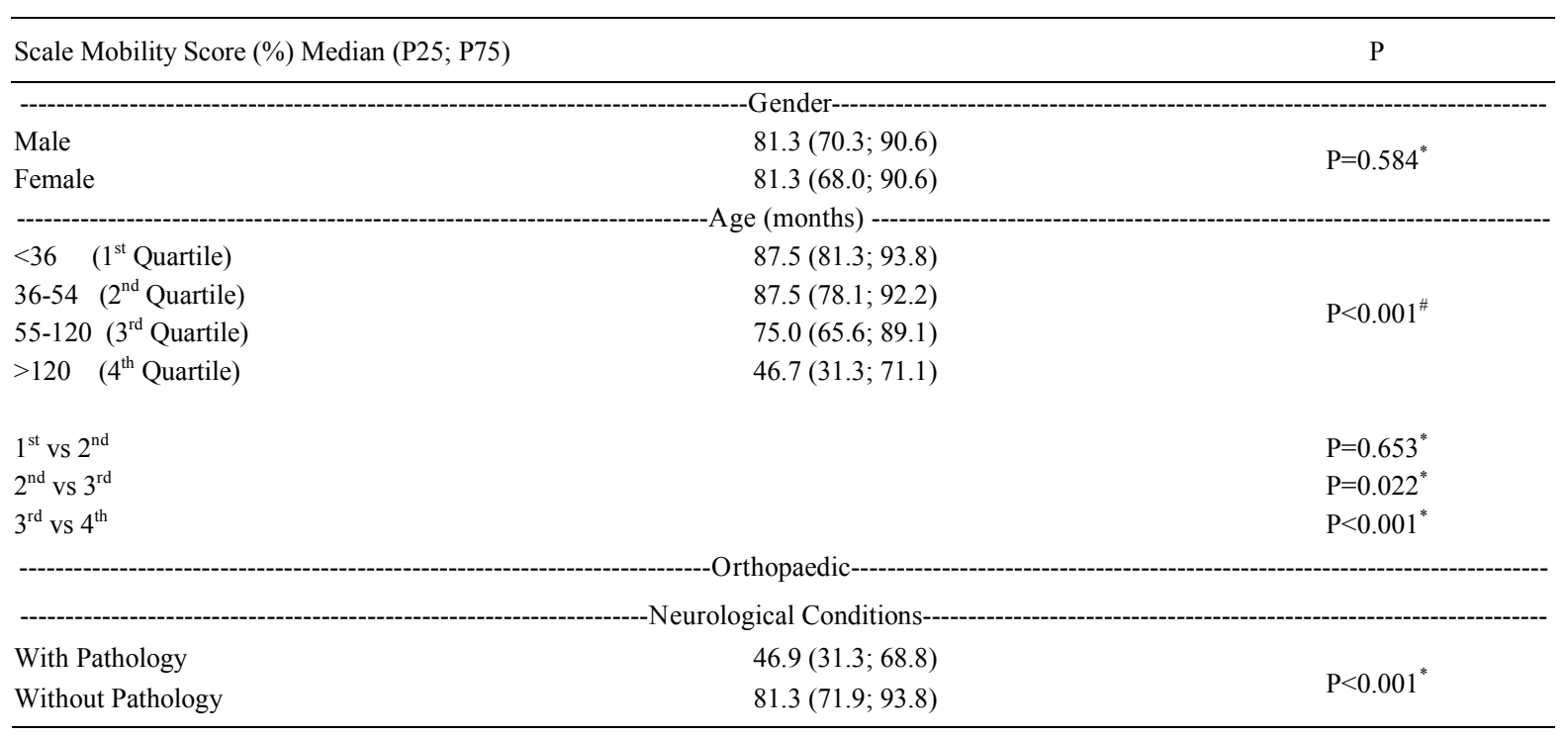

P25: 25th percentile; P75: 75th percentile.

${ }^{*}$ Mann-Whitney Test; ${ }^{\#}$ Kruskal-Wallis Test.

\section{CONFLICT OF INTEREST STATEMENT}

There is no conflict of interests or any financial or personal relationship with people or organization that could inappropriately influence this study. This is an original research that has not been published and it is not being submitted to any other journal.

\section{ACKNOWLEDGEMENTS}

The authors are grateful to all dog owners who participated in this study.

\section{REFERENCES}

BALLAGAS, A.J. et al. Pre- and postoperative force plate analysis of dogs with experimentally transected cranial cruciate ligaments treated using tibial plateau leveling osteotomy. Veterinary Surgery, v.33, p.187190, 2004. Available from: <http://onlinelibrary.wiley.com/doi/10.1111/ j.1532-950x.2004.04027.x>. doi: 10.1111/j.1532-950x.2004.04027.x.

BOYD, D.J. et al. Radiographic and functional evaluation of dogs at least 1 year after tibial plateau leveling osteotomy. Canine Veterinary Journal, v.48, p.392-396, 2007. Available from: <http://www.ncbi. nlm.nih.gov/pmc/articles/PMC1831504/pdf/cvj48pg392.pdf>.

BROWN, D.C. et al. Development and psychometric testing of an instrument designed to measure chronic pain in dogs with osteoarthritis. American Journal of Veterinary Research, v.68, p.631-637, 2007. Available from: <http://www.ncbi.nlm.nih.gov/pmc/articles/ PMC2907349/pdf/nihms213863.pdf>. doi: 10.2460/ajvr.68.6.631.

BROWN, D.C. et al. Comparison of force plate gait analysis and owner assessment of pain using the Canine Brief Pain Inventory in dogs with osteoarthritis. Journal of Veterinary
Internal Medicine, v.27, p.22-30, 2013. Available from: <http:// onlinelibrary.wiley.com/doi/10.1111/jvim.12004/epdf>. doi: 10.1111/jvim. 12004 .

BROWN, D.C. et al. Evaluation of the effect of signalment and body conformation on activity monitoring in companion dogs. American Journal of Veterinary Research, v.71, p.322-325, 2010. Available from: <http://www.ncbi.nlm.nih.gov/pmc/articles/PMC4483229/ pdf/nihms-701380.pdf>. doi: 10.2460/ajvr.71.3.322.

CHRISTOPHER, S.A. et al. Comparison of long-term outcomes associated with three surgical techniques for treatment of cranial cruciate ligament disease in dogs. Veterinary Surgery, v.42, p.329-334, 2013. Available from: <http://onlinelibrary. wiley.com/doi/10.1111/j.1532-950X.2013.12001.x/epdf>. doi: 10.1111/j.1532-950X.2013.12001.x.

COOK, J.L. Cranial cruciate ligament disease in dogs: biology versus biomechanics. Veterinary Surgery, v.39, p.270-277, 2010. Available from: <http://onlinelibrary.wiley.com/doi/10.1111/j.1532950X.2010.00653.x/epdf $>$. doi: 10.1111/j.1532-950X.2010.00653.x.

HESBACH, A.L. Techniques for objective outcome assessment. Clinical Techniques in Small Animal Practice, v.22, p.146-154, 2007.

HIELM-BJORKMAN, A.K. et al. Psychometric testing of the Helsinki chronic pain index by completion of a questionnaire in Finnish by owners of dogs with chronic signs of pain caused by osteoarthritis. American Journal of Veterinary Research, v.70, p.727-734, 2009. Available from: <http://avmajournals.avma.org/doi/ abs/10.2460/ajvr.70.6.727>. doi: 10.2460/ajvr.70.6.727.

HOLTON, L. et al. Development of a behaviour-based scale to measure acute pain in dogs. Veterinary Record, v.148, p.525531, 2001. Available from: <http://veterinaryrecord.bmj.com/ content/148/17/525.full.pdf>. doi: $10.1136 /$ vr.148.17.525.

Ciência Rural, v.46, n.12, dez, 2016. 
HSU, Y.; SERPELL, J.A. Development and validation of a questionnaire for measuring behavior and temperament traits in pet dogs. Journal of American Veterinary Medical Association, v.223, p.1293-1300, 2003. Available from: <http://avmajournals. avma.org/doi/abs/10.2460/javma.2003.223.1293>. doi: 10.2460/ javma.2003.223.1293.

HUDSON, J.T. et al. Assessing repeatability and validity of a visual analogue scale questionnaire for use in assessing pain and lameness in dogs. American Journal of Veterinary Research, v.65, p.1634-1643, 2004. Available from: <http://avmajournals. avma.org/doi/abs/10.2460/ajvr.2004.65.1634>. doi: 10.2460/ ajvr.2004.65.1634.

INNES, J.F.; BARR, A.R. Can owners assess outcome following treatment of canine cruciate ligament deficiency? Journal of Small Animal Practice, v.39, p.373-378, 1998. Available from: <http://onlinelibrary.wiley.com/ doi/10.1111/j.1748-5827.1998.tb03735.x/pdf>. doi: $10.1111 /$ j.1748-5827.1998.tb03735.x.

JANDI, A.S.; SCHULMAN, A.J. Incidence of motion loss of the stifle joint in dogs with naturally occurring cranial cruciate ligament rupture surgically treated with tibial plateau leveling osteotomy: longitudinal clinical study of 412 cases. Veterinary Surgery, v.36, p.114-121, 2007. Available from: <http://onlinelibrary.wiley.com/ doi/10.1111/j.1532-950X.2006.00226.x/pdf> doi: 10.1111/j.1532950X.2006.00226.x.

JERRE, S. Rehabilitation after extra-articular stabilisation of cranial cruciate ligament rupture in dogs. Veterinary and Comparative Orthopaedic and Traumatology, v.22, p.148-152, 2009. Available from: <http://dx.doi.org/10.3415/VCOT-07-05-0044>.

JOHNSON, J.M. et al. Rehabilitation of dogs with surgically treated cranial cruciate ligament-deficient stifles by use of electrical stimulation of muscles. American Journal of Veterinary Research, v.58, p.1473-1478, 1997.

LAVAN, R.P. Development and validation of a survey for quality of life assessment by owners of healthy dogs. Veterinary Journal, v.197, p.578-582, 2013. Available from: <http://www. sciencedirect.com/science/article/pii/S1090023313001391>. doi: 10.1016/j.tvj1.2013.03.021.

MARSH, A.P. et al. Kinematics of gait in Golden Retriever muscular dystrophy. Neuromuscular Disorders, v.20, p.16-20, 2010. Available from: <http://www.sciencedirect.com/science/article/pii/ S0960896609006609>. doi: 10.1016/j.nmd.2009.10.007.

MARSOLAIS, G.S. et al. Kinematic analysis of the hind limb during swimming and walking in healthy dogs and dogs with surgically corrected cranial cruciate ligament rupture. Journal of American Veterinary Medical Association, v.222, p.739-743, 2003. Available from: <http://avmajournals.avma.org/doi/abs/10.2460/ javma.2003.222.739>. doi: 10.2460/javma.2003.222.739.

MILLIS, D.L. Assessing and measuring outcomes. In: D.L. Millis, D. Levine, R.A. Taylor. Canine Rehabilitation \& Physical Therapy. St. Louis, MO: Saunders, Elsevier, 2004. p.211-227.

MONK, M.L. et al. Effects of early intensive postoperative physiotherapy on limb function after tibial plateau leveling osteotomy in dogs with deficiency of the cranial cruciate ligament. American Journal of Veterinary Research, v.67, p.529536, 2006. Available from: <http://avmajournals.avma.org/doi/ abs/10.2460/ajvr.67.3.529>. doi: 10.2460/ajvr.67.3.529.
POY, N.S.J. et al. Additional kinematic variables to describe differences in the trot between clinically normal dogs and dogs with hip dysplasia. American Journal of Veterinary Research, v.61, p.974-978, 2000. Available from: <http://avmajournals. avma.org/doi/abs/10.2460/ajvr.2000.61.974>. doi: 10.2460/ ajvr.2000.61.974.

QUINN, M.M. et al. Evaluation of agreement between numerical rating scales, visual analogue scoring scales, and force plate gait analysis in dogs. Veterinary Surgery, v.36, p.360367, 2007. Available from: <http://onlinelibrary.wiley.com/ doi/10.1111/j.1532-950X.2007.00276.x/pdf>. doi: 10.1111/j.1532950X.2007.00276.x

RAGETLY, C.A. et al. Inverse dynamics analysis of the pelvic limbs in Labrador Retrievers with and without cranial cruciate ligament disease. Veterinary Surgery, v.39, p.513-522, 2010. Available from: <http://onlinelibrary.wiley.com/doi/10.1111/ j.1532-950X.2010.00680.x/epdf $>$. doi: 10.1111/j.1532950X.2010.00680.x.

REID, J. Development of the short form of the Glasgow Composite Measure Pain Scale (CMPS-SF) and derivation of an analgesic intervention score. Animal Welfare, v.16, supp.1, p.97-104, 2007. Available from: <http://www.ingentaconnect.com/content/ufaw/ aw/2007/00000016/A00102s1/art00014>

SANCHEZ-BUSTINDUY, M. et al. Comparison of kinematic variables in defining lameness caused by naturally occurring rupture of the cranial cruciate ligament in dogs. Veterinary Surgery, v.39, p.523-530, 2010. Available from: <http:// onlinelibrary.wiley.com/doi/10.1111/j.1532-950X.2010.00672.x/ epdf>. doi: 10.1111/j.1532-950X.2010.00672.x.

SIWAK, C.T. et al. Age-dependent decline in locomotor activity in dogs is environment specific. Physiology \& Behavior, v.75, p.65-70, 2002. Available from: <http://www.sciencedirect.com/ science/article/pii/S0031938401006321>. doi: 10.1016/S00319384(01)00632-1.

TERWEE, C.B. et al. Quality criteria were proposed for measurement properties of health status questionnaires. Journal of Clinical Epidemiology, v.60, p.34-42, 2007. Available from: <http://www.sciencedirect.com/science/article/ pii/S0895435606001740>. doi: 10.1016/j.jclinepi.2006.03.012.

WALTON, M.B. et al. Evaluation of construct and criterion validity for the 'Liverpool Osteoarthritis in Dogs' (LOAD) clinical metrology instrument and comparison to two other instruments. Plos ONE, v.8, e58125, 2013. Available from: <http://journals. plos.org/plosone/article?id=10.1371/journal.pone.0058125>. doi: 10.1371/journal.pone.0058125.

WAXMAN, A.S. et al. Relationship between objective and subjective assessment of limb function in normal dogs with an experimentally induced lameness. Veterinary Surgery, v.37, p.241-246, 2008. Available from: <http://onlinelibrary.wiley.com/ doi/10.1111/j.1532-950X.2008.00372.x/pdf>. doi: 10.1111/j.1532950X.2008.00372.x.

WISEMAN-ORR, M.L. et al. Development of a questionnaire to measure the effects of chronic pain on health-related quality of life in dogs. American Journal of Veterinary Research, v.65, p.1077-1084, 2004. Available from: <http://avmajournals. avma.org/doi/pdf/10.2460/ajvr.2004.65.1077>. doi: 10.2460/ ajvr.2004.65.1077. 